\title{
GRUPOS DE INTERLOCUÇÃO E A "HISTÓRIA A CONTRAPE- LO": contribuições para se pensar a Pesquisa em Educação.
}

\author{
INTERLOCUTION GROUPS AND THE "HISTORY AGAINST THE GRAIN": contributions \\ to think about research in education.
}

\author{
GRUPOS E INTERLOCUCIÓN “LA HISTORIA A CONTRAPELO”: contribuciones para \\ pensar en la Investigación en Educación.
}

\author{
Marcos Britto Corrêal \\ Professor da Escola Medianeira Rede Santa Paulina. \\ Mestrando em Educação pela Universidade Federal de Santa Maria (UFSM). \\ Santa Maria - RS, Brasil. \\ marcoscorrea.filosofia@gmail.com \\ Liliana Soares Ferreira \\ Professora Doutora da Universidade Federal de Santa Maria (UFSM). \\ Santa Maria - RS, Brasil. \\ anaililferreira@yahoo.com.br
}

\begin{abstract}
RESUMO: Este artigo tem por objetivo evidenciar questões de cunho epistemológico com as quais lidam pesquisadores em Educação comprometidos com estudos na perspectiva dialética, bem como apresentar a técnica de Grupos de Interlocução, em consonância com esta perspectiva. $\mathrm{O}$ artigo explora aquilo que parece ser latente à técnica e, dialoga com Walter Benjamin sobre a possibilidade de "escovar a história a contrapelo", expondo-a como propícia à produção de conhecimento no âmbito da dialética. Foram analisados quatro trabalhos, sendo três dissertações de Mestrado e uma tese de Doutorado, que se valeram dos Grupos de Interlocução, que se trata de uma técnica que visa explicitar e compreender os sentidos da pesquisa, de maneira coletiva. A análise, tendo como suporte a perspectiva escolhida, revelou que a técnica de Grupos de Interlocução possibilita maior dialeticidade na análise e produção de dados, relacionando-a com a totalidade da problematização sobre a qual é realizada a pesquisa.
\end{abstract}

PALAVRAS-CHAVE: Pesquisa em Educação. Grupos de Interlocução. Dialética.

ABSTRACT: This paper aims to highlight questions of epistemological nature that education researchers, committed to studies with a dialetic perspective, have to deal with, as well aspresent the interlocution groups technique in consonance with this perspective. The article explores which seems to be latente to the techniqueand dialogue with Walter Benjamin about the possibility of "brush the history against the grain", exposin it as conducive to the production of knowledge within the dialetic. Four studies were analyzed: three dissertations of Master and onde Doctoral thesis, that were served of the interlocution groups, that is a technique that aims to explain and understand collectively the meanings of the research. The analysis, supported by the chosen perspective, revealed that interlocution groups technique enables higher dialeticity in data production and analisys, redirecting it with the totality of the problematization over which the research is performed.

KEYWORDS: Research in education. Interlocution groups. Dialectic.

RESUMEN: Este artículo tiene como objetivo destacar las cuestiones epistemológicas que tienen que ver con los investigadores educativos comprometidos con estudios en perspectiva dialéctica y la técnica de los grupos de interlocución en línea con esta perspectiva. El artículo explora lo que parece ser la técnica y los diálogos con Walter Benjamin acerca de la posibilidad de la "historia el cepillo a contrapelo", exponiendo como conducente a la producción de conocimiento dentro de la dialéctica. Se analizaron cuatro estudios, tres tesis de Maestría y una tesis Doctoral, que se valió a los grupos de interlocución, que es una técnica que trata de explicar y entender el significado de la investigación colectivamente. El análisis, con el apoyo de la perspectiva elegida, reveló que la técnica de grupos de interlocución permite que los datos de análisis dialéctico y de producción más altos, relacionándolo con todo el cuestionamiento sobre la que se realiza la pesquisa.

PALABRAS CLAVE: Investigación en Educación. Grupos de interlocución. Dialéctica.

Artigo recebido em maio de 2017

Aprovado em julho de 2017 


\title{
1| INTRODUÇÃO: A DIALÉTICA E DEMANDAS PARA A PESQUISA EM EDUCAÇÃO
}

Não se faz pesquisa sem que se esteja inserido na História. E, como tal, a dialética se apresenta como uma perspectiva teórica e metodológica apropriada para o estudo da sociedade e, neste caso, tema sobre o qual se pesquisa. Para nos fazer pensar sobre tal assertiva e subsidiando esta, o filósofo alemão Walter Benjamin, em suas teses sobre "O Conceito de História", ressalta qual seria o papel do historiador comprometido com o Materialismo Histórico Dialético (MHD):

\begin{abstract}
Todos os que até hoje venceram participam do cortejo triunfal, em que os dominadores de hoje espezinham os corpos dos que estão prostrados no chão. Os despojos são carregados no cortejo, como de praxe. Esses despojos são o que chamamos bens culturais. $O$ materialista histórico os contempla com distanciamento. Pois todos os bens culturais que ele vê têm uma origem sobre a qual ele não pode refletir sem horror. Devem sua existência não somente ao esforço dos grandes gênios que os criaram, como à corveia anônima dos seus contemporâneos. Nunca houve um monumento da cultura que não fosse também um monumento da barbárie. $E$, assim como a cultura não é isenta de barbárie, não o é, tampouco, o processo de transmissão da cultura. Por isso, na medida do possível, o materialista histórico se desvia dela. Considera sua tarefa escovar a história a contrapelo. (BENJAMIN, 1994, p. 225)
\end{abstract}

Como olhar com distanciamento estes bens culturais sabendo que estamos nós já inseridos no social? Como não se prostrar com horror diante de uma sociedade onde se produz cultura ou mesmo ciência, que, subjacentemente a si, esconde seu próprio desenvolvimento e construção? Benjamin (1994) elabora poeticamente um caminho que pode ser trilhado pelo pesquisador que se apresenta como materialista histórico. Ou seja, para responder às questões, é necessário "escovar a história a contrapelo"1 para, quiçá, não apenas reproduzir, mas analisar criticamente como a História, a cultura e mesmo a ciência estão sendo produzidas. Qual seria então um critério de verdade para a produção de conhecimento, com base na dialética como aporte teórico e metodológico?

Em seu livro sobre pesquisa, Triviños (2008) apresenta o mesmo questionamento acerca do critério de verdade e lança luz sobre o tema dentro do Materialismo Histórico Dialético - MHD. Para este autor, na senda crítica de Benjamin naquilo que tange ao conhecimento, esta Teoria tem como critério de verdade a prática social; assim "a prática é o critério decisivo para reconhecer se um conhecimento é verdadeiro ou não" (TRIVIÑOS, 2008, p. 27). Por conseguinte, na prática, nas relações sociais e, portanto, o sujeito, em interlocução ${ }^{2}$ com outros sujeitos, com seu trabalho e história, permite que se evidenciem as categorias, que, assim, podem ser problematizadas pelo pesquisador. Antes de mais nada, para o MHD os seres humanos agem sobre o mundo a fim de superar suas necessidades e esta ação constitui a existência humana. Nesse sentido, desconfiamos que o autor esteja se referindo à práxis (e, adiante, retomaremos essa desconfiança) na perspectiva defendida por Vàzquèz, que expressa na pontual introdução elaborada por Francisco

\footnotetext{
${ }^{1}$ Abordamos a expressão benjaminiana em sentido crítico de compreender a História, denotando, assim, a necessidade de compreendê-la como totalidade. Se não percebida desta maneira, acabará por evidenciar apenas uma parcialidade unilateral. Portanto, esta abordagem corresponde à categoria "Totalidade" para o Materialismo Histórico Dialético, pois a criticidade, contida na expressão benjaminiana, evidencia as diversas determinações que produzem um fenômeno.

${ }^{2}$ Entende-se este termo com base no sentido que Marques (1996) Ihe atribui: a prática da linguagem é sempre interação, pressupõe que os sujeitos estejam envolvidos em uma situação dialógica, uma relação eu-tu: "Interlocução que não é simples amálgama de saberes prévios, o trespasse de uns nos outros; mas é aprender contra o previamente aprendido, negação do que já se sabe na constituição do novo saber, de saberes outros" (MARQUES, 1996, p. 14).
} 
José Martinez para a obra "Filosofia da Práxis" (2007): as práxis individuais são intencionais na medida em que, conscientemente, realizam os objetivos dos sujeitos, produzindo resultados "[...] e dado que esses resultados geralmente não costumam coincidir com as intenções dos sujeitos que os produzem, faz-se muito útil lançar mão da noção de práxis não intencional para explicar o desenvolvimento histórico" (MARTINEZ, 2007, p. 16). Karel Kosik, em sua obra "Dialética do Concreto" (1976), também deixa sintetizada em poucas palavras esse pressuposto sobre a ação humana, pois para o MHD "a 'coisa em si', de que trata a Filosofia, é o ser humano e o seu lugar no universo, ou (o que em outras palavras exprime a mesma coisa): a totalidade do mundo revelada pelo homem na história e o homem que existe na totalidade do mundo" (KOSIK, 1976, p. 230). Sobre a pesquisa, novamente Triviños $(2008$, p. 56) expõe com cuidado essa problemática importante na Teoria marxiana, ressaltando, portanto, que nesta perspectiva são os condicionantes econômicos, históricos e sociais constituídos pelos seres humanos, mesmo contra sua vontade, que coadunam o modo como o mundo é significado. Desta forma, toda nossa reflexão e ciência acerca dos fenômenos que se apresentam diz respeito não ao mundo em si, mas à significação que constituímos sobre estes fenômenos e ainda, significados estes, produzidos pelos seres humanos ao longo da História, de modo que, modificando o mundo, modificam-se eles próprios em âmbito concreto.

Com base nessas questões, sistematizamos argumentos nesse texto, com a intenção de colocar em relevo questões de cunho epistemológico com as quais lidam pesquisadores em Educação comprometidos com estudos na perspectiva dialética. Bem como, intencionamos apresentar a técnica de Grupos de Interlocução em consonância com esta perspectiva teórica. Deste modo, o artigo explora características e elementos latentes à técnica e, dialoga com Walter Benjamin sobre a possibilidade de "escovar a história a contrapelo", expondo-a como propícia à produção de conhecimento no âmbito da dialética.

Como campo empírico, foram analisados quatro trabalhos, sendo três dissertações de Mestrado e uma tese de Doutorado, que, na produção e análise de dados, se valeram da técnica de Grupos de Interlocução. Os trabalhos foram selecionados por essa característica: conterem na descrição metodológica, na produção e análise de dados, essa técnica, a qual será descrita mais detalhadamente na terceira seção. Ao escolher esse campo empírico, estabeleceu-se como critério a busca por pesquisadores em educação e por ações de Pesquisa em Educação nas quais se evidenciasse uma interação práxica, ou seja, uma oportunidade de os sujeitos da pesquisa (pesquisadores e interlocutores) juntos agirem de modo consciente e transformador. Desse modo, entendemos contemplar a historicidade, a práxis e a realidade como categorias dialéticas orientadoras dessa sistematização, as quais se evidenciam a seguir, nas seções que integram esse texto.

\section{2| PESQUISA EM EDUCAÇÃO}

Especialmente nas Ciências Humanas - de onde podemos falar com maior segurança - pressupomos que, havendo um objeto a ser pesquisado este, por sua vez, é visado pelo pesquisador, denotando, assim, antes de tudo, certa abordagem intencional sobre o que será pesquisado. Essa visada pressupõe uma intenção do pesquisador que, neste sentido, é importante ser fundamentada, pois consciente ou não dela, haverá interferência no processo de sua investigação frente à pesquisa. Sendo assim, pressupomos que conhecer uma concepção epistemológica acerca da ciência que fundamente sua metodologia de pesquisa será fundamental para o bom desenvolvimento de seu trabalho. Entendemos que se não houver uma relação contínua entre método, pesquisa e concepção epistemológica, o pesquisador estará envolto em contradições entre seus 
objetivos e a sistematização de sua pesquisa. Essa problemática é mais evidente para pesquisas comprometidas como o MHD, como pode ser visto adiante.

Triviños (2008) aplica o termo "prática social" como critério de verdade para o MHD, contudo apresentamos aqui uma pequena digressão para problematizar o termo. Em nosso entender e por opção teórica, o termo utilizado pelo Autor objetiva a mesma significação que "práxis", porém, este termo configura maior alcance semântico comportando de melhor forma aquilo que representa para o MHD a capacidade humana de constituir-se como ser humano no mundo, valendo-se da natureza para efetivar sua história. Karel Kosik (1976), nas páginas iniciais de sua já citada obra, expõe os critérios da práxis, ao afirmar que atitude primal do ser humano sobre a realidade supera a atitude do sujeito que pensa, para constituir-se como ser humano de ação teleologicamente elaborada e prática, sendo, então, sujeito: "[...] histórico que exerce a sua atividade prática no trato com a natureza e com os outros homens, tendo em vista a consecução dos próprios fins e interesses, dentro de um determinado conjunto de relações sociais" (KOSIK, 1976, p. 09). Nesse processo, a realidade, para Kosik:

[...] não se apresenta aos homens, à primeira vista, sob os aspectos de um objeto que
cumpre intuir, analisar e compreender teoricamente, cujo polo oposto e complementar
seja justamente o abstrato sujeito cognoscente que existe fora do mundo e apartado do
mundo; se apresenta como o campo em que se exercita sua atividade pratico-sensível,
sobre cujo fundamento surgirá a imediata intuição prática da realidade. No trato prático
utilitário com as coisas é em que a realidade se revela como mundo dos meios, fins, in-
strumentos, exigências e esforços para satisfazer a estas - o indivíduo "em situação" cria
suas próprias representações das coisas e elabora todo um sistema correlativo de noções
que capta e fixa o aspecto fenomênico da realidade. (Kosik, 1976, p. 10).

Assim, a práxis como ação do ser humano sobre o mundo se constitui em nosso entender como conceito mais adequado à complexidade e dimensão deste agir. Para além da "prática social", a práxis comporta em si tanto a intenção do agente quanto sua não intencionalidade, e é dessa forma, que se produz a historicidade humana. No contexto capitalista, entretanto, a práxis pode se constituir em mera prática reiterativa, como é o caso do trabalho alienado, no qual o trabalhador produz um objeto que lhe é estranho, interessando-o, no entanto, apenas o salário pago por sua mão-de-obra.

Após essa digressão acerca do uso dos termos "prática social" ou "práxis", retomemos a ideia no que diz respeito às especificidades do MHD quanto à Pesquisa em Educação. De tal modo, para o Materialismo, a matéria existe independentemente de haver ou não um observador, para nós, sujeitos de linguagem ${ }^{3}$, o que há é a significação acerca dos fenômenos no mundo, impingindo neste movimento de significação nossos pressupostos histórico-sociais. Portanto, ao visarmos um objeto a ser pesquisado nos deparamos, antes de tudo, com uma gama de categorias (LUKÁCS, 2010) que são inferidas sobre ele. Tendo como exemplo de objeto a Educação, as categorias revelam nossa compreensão acerca do que envolve este conceito, podendo vinculá-lo a escolas, à família, ao conhecimento, ou mesmo a um modo de ascensão social. A título de exemplo, Frigotto (2010) enfatiza, em "A Produtividade da Escola Improdutiva", uma crítica à visão de

\footnotetext{
${ }^{3} \mathrm{~A}$ Linguagem é em nosso caso diferente em relação a dos outros animais, assim "Este comércio da palavra é o laço de toda a sociedade doméstica e civil". Aristóteles (2006), na "Política", assevera a gênese dos questionamentos acerca da Linguagem e nos reportamos a ele para ressaltar que o som, o mero flatus vocis, proferido pelos seres humanos, ganha significado especial para sua espécie, isto é, se faz em comunicação tridimensional, presente, passado e futuro e, por essa razão, a linguagem humana vai além do dado.
} 
escola como espaço de ascensão social proposto pela Teoria do Capital Humano. A crítica feita pelo autor, diz respeito à Teoria do Capital Humano pressupor que, mesmo um sujeito não tendo capital, nem os meios de produção, nada o impede de ascender socialmente, pois "[...] uma vez que o indivíduo, investindo em capital humano poderá aumentar sua renda" (FRIGOTTO, 2010, p. 61) e, assim, individualmente, por meio da Educação, acessar melhores empregos e ter melhores condições de vida. Com efeito, quanto ao exemplo, nos deparamos com um objeto estritamente histórico em movimento. São as categorias que definem o ser e "de sua mera facticidade segue-se uma série de determinações que produzem um ser humano-real" (FRIGOTTO, 2010, p. 80). A análise das categorias, entrementes, deve compreender que a História se efetiva quando os "homens entram em relações determinadas, necessárias, independentes de sua vontade, [...] onde essas determinam um grau de desenvolvimento das suas forças produtivas" (MARX, 2008, p. 47), nos colocando assim, a necessidade iminente de, ao produzir uma pesquisa, buscar o método mais apropriado para analisar essas categorias de modo dialético, não as concebendo, portanto, como estanques, que, nas palavras de Kosik (1976), corresponderia à pseudoconcreticidade. Para Kosik (1976), a pseudoconcreticidade seria o mundo das relações imediatas, onde não há práxis humana intencional, mas sim a falsa verdade das aparências. No Capitalismo, como sujeitos alienados em relação ao trabalho, constituímos uma compreensão de mundo não real, mas apenas aparente, fetichizada pela produção da mais-valia e do trabalho como mercadoria.

As peculiaridades da Pesquisa em Educação comprometida com a teoria marxiana superam a simples exposição ou coleta de dados, pois a produção de conhecimento neste horizonte está ligada diretamente a categorias e leis da Dialética, ou seja, a Razão não é compreendida como um fim, mas como um resultado das relações histórico-sociais. Triviños (2008, p. 54) explora as categorias do Materialismo Dialético, ressaltando três principais: a matéria, como independente do ser humano; a consciência, como compressão da história humana e transformação da matéria; sendo por fim, a práxis, como relação na qual o ser humano, mudando a matéria, muda a si mesmo. Os pesquisadores, assim vinculados à esta teoria, assumem criticamente as categorias. Esta posição é, antes de mais, por-se criticamente como sujeito da pesquisa, de modo que as categorias propiciem uma análise da sociedade, concebendo-a como histórica, produzida pelos seres humanos e vendo estes como sujeitos ativos de sua realidade. E, nesta posição, não pode apenas analisá-los de forma neutra ou idealizada. Portanto, toda ação, sob forma de pesquisa, pressupõe mudança na realidade e, assim, produção de dados e de conhecimentos.

Reforçamos que, neste contexto, não há "coleta" de dados em pesquisa, pois os únicos dados aos quais temos acesso, são, na realidade, produto de nossas relações histórico-sociais e por esta razão, estão propícios a alterações que impossibilitem um conhecimento estanque, pronto para ser "coletado". Relações histórico-sociais estas constituídas, pois, pela pseudoconcreticidade, que salta à frente dos pesquisadores, intencionando antes o produto de sua pesquisa. Com efeito, não há pesquisa neutra, por não haver linguagem independente de algum horizonte conceitual e de relações de poder dados os antagonismos próprios de cada classe social.

Ao tratar também sobre o tema da epistemologia sob o viés do MHD, em uma de suas obras essenciais, "Ciência e Existência", Álvaro Vieira Pinto, assinala que o pensamento humano criou uma bifurcação na possibilidade de entender o mundo. Suas palavras permitem compreender em que sentido o Materialismo se difere na bifurcação apresentada por ele, pois "de um lado, acreditou-se que o pensamento constitui um reino original e irredutível por essência ao da realidade material circundante" (VIEIRA PINTO, 1969, p. 64, grifo nosso). O Idealismo e o Racionalismo se fundam nesta concepção. Por outro lado, seriam as "idéias o reflexo, no plano da organização nervosa superior, da realidade e leis dos processos que se passam no mundo exterior, os quais não dependem do pensamento" (VIEIRA PINTO, 1969, p. 64). Assim, a realidade tem "suas leis específicas, 
as únicas reais, de modo que só compete à reflexão racional apoderar-se das determinações existentes entre as próprias coisas e fenômenos" (VIEIRA PINTO, 1969, p. 64). A Dialética está vinculada a este segundo pressuposto e as categorias, como dito acima, partem da "captação subjetiva da realidade" (VIEIRA PINTO, 1969, p. 64). Essa captação subjetiva, entrementes, tem sua origem nas relações de produção dos seres humanos frente à matéria, como sublinhado por Triviños (2008, p. 55), uma vez que "[...] as categorias se formaram no desenvolvimento histórico do conhecimento e na prática social."

Em suma, alguns pressupostos como a busca de compreender a totalidade que constitui uma categoria, a compreensão da prática como critério de verdade e, enfaticamente, reconhecer que o conhecimento comprometido com a teoria marxiana se constitui como ação que modifica a realidade, são demandas dos pesquisadores que se valem deste aporte teórico-metodológico para a produção de seu trabalho. Com essa caracterização epistemológica da Pesquisa em Educação sob o viés do MHD, propomos, a seguir, um olhar mais atento sobre uma técnica de pesquisa, o "Grupo de Interlocução". Esta técnica em nosso entendimento, como será exposto a seguir, vincula-se diretamente às demandas originadas pela Pesquisa em Educação vinculada à teoria, portanto, se propõe a "escovar a história a contrapelo", de modo a reconhecer que a pesquisa, por si, já configura mudanças na elaboração práxica da historicidade.

\section{3| GRUPOS DE INTERLOCUÇÃO E A "HISTÓRIA A CONTRAPELO"}

Em grande medida, produzimos ciência normal, como Thomas Kuhn (1978) já caracterizou, ao escrever que essa "significa a pesquisa firmemente baseada em uma ou mais realizações científicas passadas” (KUHN, 1978, p. 29). Essa ciência normal, fortemente dualista, seja pela lógica dedutiva, seja pela indutiva, é densamente aplicada nas Ciências Exatas ou Naturais. Contudo, tais métodos prioritariamente não correspondem às demandas, necessidades e problemas sociais, conduzindo, por vezes, no plano da lógica, a "erros, ou a absurdos" (TRIVIÑOS, 2008, p. 27) que não são compatíveis com a dinâmica da sociedade humana.

Nestes termos, mesmo com seus limites acerca da sociedade humana, a Lógica Formal (dedutiva ou indutiva), ainda assim, se efetiva por instituir importantes critérios de verdade. Desde Aristóteles até a ciência moderna, a "razão racionalista" (KOSIK, 1976) apregoa a onipotência, quer seja das ideias, quer seja do cogito e, portanto, do sujeito atomizado como detentor da verdade. Essa posição, pois, da Lógica Formal é fortemente atacada pela teoria marxiana, como ficou mais evidente a partir da primeira parte deste texto e assim, no MHD, a Dialética é apresentada como lógica mais significativa para a produção do conhecimento por vincular a historicidade e o movimento de mudança do mundo para além do plano formal. Esta teoria, por sua vez, é caracterizada por compreender o conhecimento como algo transitório, fruto das relações sociais e dos antagonismos de classe. Portanto, temos aqui outro critério de verdade, como dito, a práxis ou, nas palavras de Triviños (2008), como já referido, a prática social.

Os problemas expostos até então, ganham significado especial no artigo "Grupos de Interlocução como técnica de produção e sistematização na Pesquisa em Educação" no qual, suas autoras, todas envolvidas diretamente com a Pesquisa em Educação, tendo como aporte teórico e metodológico o MHD, apresentam a proposta da técnica "Grupos de Interlocução". Esta proposta, com suas peculiaridades e por definir os Grupos de Interlocução como "mais do que um grupo de discussão, constituem-se em grupos de interação nos quais os participantes passam a se influenciar mutuamente, socializando suas experiências a partir da linguagem" (FERREIRA et al., 2014, p. 207), enfatizando assim, seu caráter prático, vai ao encontro das necessidades da Pesquisa em 
Educação com base no MHD. Deste modo, a técnica representa uma possibilidade de análise em outras perspectivas e critérios de verdade para além da ciência normal. Perspectivas estas, ligadas às categorias sublinhadas por Triviños (2008), e, por esta razão, fundamentadas na Lógica Dialética e na práxis. Assim, subsidiada pela teoria marxiana, a técnica de Grupos de Interlocução visa a contribuir para uma produção e sistematização de dados "a contrapelo" na Pesquisa em Educação. Em suma, a técnica de Grupos de Interlocução é "mais que uma coleta de dados, apresentação ou qualificação de dados, é um momento de problematização conjunta acerca da pesquisa" (FERREIRA et al., 2014, p. 207). Os dados produzidos em uma pesquisa, com base, por exemplo, em entrevistas, exige a análise dos discursos dos interlocutores de forma coletiva em uma problematização no Grupo de Interlocução. Nesse momento, reúnem-se pesquisadores e interlocutores ocorrendo o encontro entre os envolvidos na pesquisa para, juntos, analisarem as primeiras significações dos discursos propostas pelo(s) pesquisador (es). Estes, então, apresentam suas primeiras elaborações a partir da análise dos discursos e as submetem à discussão e reelaboração. Por esse motivo, se trata de uma técnica de produção e de análise de dados, como explica Ferreira (2006, p. 40), ao relatar como procedeu nos grupos de interlocução, por ocasião da pesquisa que subsidiou sua tese de doutoramento:

"[...] expus a minha leitura dos discursos e incentivei o aprofundamento das discussões, trazendo noções, aportes teóricos para dissipar dúvidas e incentivando indagações, solicitando esclarecimentos acerca de elementos cuja análise eu queria aprofundar, como salário e satisfação em ser professora".

Esta técnica, desenvolvida em consonância com a prática do KAIRÓS - Grupo de Pesquisas e Estudos sobre Trabalho, Educação e Políticas Públicas ${ }^{4}$ sintetiza a busca daqueles pesquisadores comprometidos com o MHD. Dos trabalhos analisados neste texto, percebemos que estes pesquisadores encontram limites epistemológicos, no momento de sistematização dos dados produzidos ou mesmo se sentem desconfortáveis em simplesmente analisar os dados e sistematizá-los sem que os envolvidos na pesquisa (interlocutores) possam enxergar-se, refletir acerca de si. Desta forma, o espaço de interlocução leva os participantes à análise de modo protagonista, podendo, inclusive, ressignificar as análises produzidas pelo(s) pesquisador (es). A afirmação: "o Grupo de Interlocução é um complemento da pesquisa, não sendo a única técnica" (FERREIRA et al., 2014, p. 203) de produção de dados, ratifica os limites que a Lógica Dialética sofre no âmbito da pesquisa acadêmica, o que expressa a necessidade destes pesquisadores de criar técnicas e métodos que melhor se relacionem aos interesses e objetivos de suas pesquisas. Portanto, o Grupo de Interlocução deve ser associado a outras técnicas como a entrevista, a observação, os grupos focais, a pesquisa survey, a análise documental, entre outras, para que a produção dos dados seja ampla e o estudo abarque a complexidade do fenômeno estudado.

Na prática da técnica denominada Grupo de Interlocução, após serem produzidos os dados da pesquisa, o grupo se constitui pela diversidade dos sujeitos que, coletivamente, constroem a análise do trabalho realizado até então pelo pesquisador. Nesse coletivo, aquele que produz a pesquisa tem a oportunidade de propiciar um retorno daquilo que ele produziu, superando a ideia de que pesquisa é somente "coletar" dados sem que os sujeitos pesquisados tenham participação nos resultados dessa "coleta". Sendo assim, a unidade dos dados é posta em diálogo com a diversidade do grupo e, cada sujeito, por meio da linguagem e do contexto que os agrega, expressa

\footnotetext{
${ }^{4}$ O Grupo Kairós, desde 2008, na Universidade Federal da Santa Maria, produz pesquisa nos temas Trabalho, Educação e Políticas Públicas, a partir de uma perspectiva Materialista Histórica Dialética dos fenômenos sociais.
} 
suas ponderações, não raramente, apresentando novos sentidos aos dados analisados. A relação dialógica fundamental nos grupos de interlocução propicia ao pesquisador, portanto, acessar dados e problemas que não teria alcançado, não fosse este espaço. Da mesma maneira, os interlocutores da pesquisa podem (re) conhecer sentidos, questões e categorias explicitadas individualmente no grupo como sentidos, questões e categorias, mas que, em interlocução, são dados do coletivo, caracterizam esse coletivo e merecem ser analisados por todos.

Por acessar dados novos e propiciar um espaço de maior relação social no âmbito da pesquisa qualitativa em Educação, a técnica Grupos de Interlocução proporciona ao pesquisador analisar de modo mais crítico a realidade. No Grupo de Interlocução, o pressuposto de "escovar a história a contrapelo", salientado por Benjamin (1994), ganha maior evidência, pois a realidade dos sujeitos da pesquisa se destaca para além da intenção do pesquisador. Este, portanto, terá maior possibilidade de dialetizar os dados produzidos, confrontando, assim, suas expectativas com a teoria e com a realidade objetiva do pesquisado.

\section{4 | DIANTE DE TANTOS LIMITES, QUAIS AS POTENCIALIDADES?}

Nas pesquisas produzidas pelo Grupo KAIRÓS nos últimos dois anos, quatro pesquisadoras ${ }^{5}$ trabalharam com a técnica de Grupos de Interlocução. São, nos trabalhos destas pesquisadoras, que apresentaremos contribuições sobre a técnica abordada nesse texto. Destes, procuraremos evidenciar o quanto os grupos contribuíram em uma análise dos dados que se propõe ser dialética. De tal modo, mais uma vez Benjamin, na Tese 3, "Sobre o Conceito de História" (1994), permite caracterizar o papel do historiador e, por que não, da pesquisa baseado no MHD. Para aquele autor alemão o sujeito "que narra os acontecimentos, sem distinguir entres os grandes e pequenos, leva em conta a verdade de que nada do que um dia aconteceu pode ser considerado perdido na história" (BENJAMIN, 1994, p. 223). Esta perspectiva de compreensão da totalidade pesquisada, com a contribuição do Grupo de Interlocução, nas palavras de Fiorin (2012) - primeira autora a se valer do Grupo de Interlocução em sua pesquisa - coopera com a maior "percepção do contexto no qual estão inseridas as pedagogas e da possibilidade de mudança em seu trabalho e, até mesmo, de suas concepções" (FIORIN, 2012, p. 20). Em nosso entender, a Autora, implicada em uma pesquisa sobre o Trabalho Pedagógico de Pedagogas, demonstra, em sua dissertação, como o grupo ao fomentar a interlocução na totalidade dos sujeitos com os dados da pesquisa, corrobora com a perspectiva de "escovar história a contrapelo". Nesta perspectiva, os dados são confrontados com a historicidade do grupo, permitindo o acesso não apenas às conclusões do pesquisador, mas favorecendo também, a manifestação crítica e contributiva acerca da pesquisa e a maior compreensão das categorias, evidenciadas por todos, na entrevista particular e no Grupo de Interlocução.

Como ficou evidenciado acima, a produção de dados na Pesquisa em Educação pautada pela ciência normal acaba por limitar em grande medida a análise dialética destes. Maraschin (2015) enfatiza que o "Grupo de Interlocução, que objetivou ser um complemento da pesquisa serviu para a reflexão sobre os dados construídos a partir das técnicas de observação, entrevistas e grupo focal" (MARASCHIN, 2015, p. 65). Deste modo, o que destaca a Autora é o fato de não ter abandonado

\footnotetext{
${ }^{5}$ As Dissertações de Mestrado de Bruna Pereira Alves Fiorin (2012); Isabel D. Weber Machry Rodrigues (2013); Taise Tadielo Cezar (2014) e a Tese de Doutorado de Mariglei Severo Maraschin (2015). Todas sob Orientação da Prof $^{a}$ Dra $^{a}$. Liliana Soares Ferreira.
} 
outras técnicas de pesquisa, mas observa que o Grupo de Interlocução contribui na produção dos dados, bem como também reforça Fiorin (2012) que, tendo se aplicado questionários, percebeu que o grupo possibilitou "além de análises de categorias a priori, o surgimento de um novo leque de categorias a partir dos discursos dos sujeitos da pesquisa" (FIORIN, 2012, p. 23).

Percebemos que o Grupo de Interlocução possibilita, em primeiro lugar, uma relação de maior responsabilidade ética por parte do pesquisador. Desse modo, compreendemos como sendo responsabilidade do pesquisador em Educação contribuir para que todos os sujeitos da pesquisa saibam os fins desta, bem como, tenham acesso aos seus resultados. Dado o fato de muitos pesquisadores não retornarem sua produção aos sujeitos da pesquisa, deixando-os sem conhecer os resultados ou mesmo os objetivos de seu trabalho, no que diz respeito aos Grupos de Interlocução, este problema é sanado, tornando-se, ao contrário, um momento de produção coletiva, pois propicia para os sujeitos da pesquisa um momento de produção e reflexão acerca dos dados em conjunto com o pesquisador. Em segundo, este momento de interlocução leva o pesquisador a encontrar questões, categorias e (re) pensar seu trabalho até então. Sabe-se o quão raras são as oportunidades de os sujeitos poderem refletir coletivamente sobre o trabalho que produzem, e, deste modo, poder iniciar planejamentos de ações que revigorem e reelaborem seu trabalho. As categorias que são evidenciadas no grupo e a possibilidade de os sujeitos refletirem sobre sua realidade contribuem profundamente para uma relação mais profícua entre os sujeitos da pesquisa e o pesquisador, bem como com o trabalho realizado por ambos.

No trabalho produzido por Taise Cezar (2014, p. 72), temos uma oportuna descrição de como se constituiu o Grupo de Interlocução na pesquisa da autora:

\begin{abstract}
O momento do Grupo de Interlocução foi planejado e realizado sob a forma de uma roda de conversa, em que inicialmente os sujeitos se apresentaram, pois nem todas se conheciam até esse encontro. Foram utilizados slides, como recurso visual para a apresentação da pesquisa pela pesquisadora, também o grupo teve o suporte de uma pessoa externa, convidada pela pesquisadora e conhecedora do estudo, que auxiliou na gravação do áudio, no registro fotográfico e escrito dos discursos produzidos no grupo.
\end{abstract}

Cada grupo, dada a dinamicidade de sujeitos, pode recorrer a diferentes modos de organização, mas mantendo ainda assim certos passos de organização. Fiorin (2012, p. 20), sendo a primeira pesquisadora a trabalhar com o Grupo de Interlocução, propõe sete passos tidos como "básicos" para a organização:

1 - exposição da proposta do Grupo de Interlocução para os sujeitos da pesquisa;

2 - apresentação de slides com os resultados da pesquisa e da coleta de dados inicial incial;

3 - discussão sobre os resultados da pesquisa;

4 - apresentação de questões que surgiram após a análise dos dados;

5 - discussão sobre as novas questões apresentadas buscando ampliar a pesquisa e suprir algumas lacunas que possam ter ficado em relação à coleta de dados inicial;

6 - oportunizar um espaço em que os sujeitos exponham dúvidas sobre o tema ou sobre a pesquisa;

7 - esclarecimentos e sistematização.

Um grupo de estudos, um pesquisador ou mesmo um estudioso solitário, mas atendo a dimensão que os conceitos têm, assim como as mudanças que estes sofrem histórica e socialmente, sempre estará sujeito a ressignificar o modo como os discursiva. Os pesquisadores que integram o Grupo Kairós, em seu início, no ano de 2008, naquela época, se valiam da expressão 
"coleta de dados", quando se referiam à atividade de produção de dados na Pesquisa em Educação. Contudo, tal expressão foi substituída em trabalhos posteriores no interior do grupo por "produção de dados". Compreendemos que a expressão "produção de dados", representa, de modo mais evidente, o trabalho realizado em consonância com o MHD, pois este percebe os sujeitos da pesquisa, assim como o conhecimento, não como algo estanque, uma coleta, uma extração, e sim os sujeitos como ativos e concretizados a partida da práxis que constitui, por conseguinte, o conhecimento. Isabel Rodrigues (2013, p. 26) corrobora este argumento em sua dissertação, ao afirmar que o Grupo de Interlocução "se diferencia de outras propostas, porque não é um momento de 'coleta' de dados, e, sim, uma maneira sistemática de dar retorno aos participantes Ihes permitindo acompanhar e participar também dos encaminhamentos."

Se compreendemos que é importante não "distinguir entre pequenos e grandes" acontecimentos ao se narrar uma história e se essa perspectiva nos é cara no que tange à Pesquisa em Educação pautada pelo MHD, não podemos deixar de perceber que a totalidade do objeto pesquisado se faz mais clara com a contribuição da técnica de Grupos de Interlocução. Impasses, questionamentos, contribuições e mesmo críticas são postas para o pesquisador e os sujeitos da pesquisa acerca do objeto pesquisado no Grupo de Interlocução.

\section{6| CONSIDERAÇÕES FINAIS}

Escrever é um trabalho enfaticamente feito na solidão, por mais que compartilhado, feito a "quatro mãos" ou mais; por mais que se escreva sempre dentro da História, seja sobre si mesmo, sobre outro ou para outros, trata-se de um ato que denota uma ação solitária. Por esta razão, um pesquisador vinculado ao MHD, sabendo-se só em sua escrita e na sistematização daquilo que produz, não pode se furtar à interlocução. "Escovar a história a contrapelo" é se colocar na busca de compreender a concreticidade dos fenômenos, é estar atento à historicidade, às categorias dialéticas e à materialidade que constitui a práxis humana. Os trabalhos aqui referenciados, que se valeram da técnica de Grupos de Interlocução, os temas diversos que vão do trabalho de pedagogas, de políticas públicas, do trabalho pedagógico às disputas que se concretizam nas relações de trabalho no âmbito da Educação, se constituem na busca de produzir conhecimento comprometido com o MHD.

Após analisar esses trabalhos, podemos reiterar que a Pesquisa em Educação, no âmbito do $\mathrm{MHD}$, demanda necessidades que transcendem àquilo que notadamente é reproduzido em concepções epistemológicas não dialéticas. Quem comprometido com o Materialismo, não busca simplesmente a coerência do conhecimento para com o próprio conhecimento, pois compreende que este não existe por si, como no caso do Positivismo Lógico (TRIVIÑOS, 2008, p. 36), mas em decorrência das relações sociais econômicas e históricas. Esta compreensão, portanto, é necessariamente crítica e exige uma atitude na qual o pesquisador precisa perceber a práxis humana e possibilitar uma análise dialética das categorias.

A técnica de Grupos de Interlocução, por ser um momento prioritariamente dialógico e de relações diretas entres os sujeitos da pesquisa, se apresenta como técnica favorável a ser aplicada em Pesquisa em Educação que tenham o MHD como aporte teórico e metodológico. Destacamos, também, que, para além deste momento de interlocução entre os sujeitos, a técnica propicia ao pesquisador uma relação mais profícua entre suas intenções e a sistematização dos dados produzidos em sua pesquisa. Por esse motivo, compreendemos que a técnica de Grupos de Interlocução proporciona ao pesquisador maior possibilidade de dialetizar sua produção de dados. Esta característica, por sua vez, potencializa o viés crítico e a capacidade de "escovar a história a 
contrapelo", uma vez que, as categorias são postas em análise não apenas por parte do pesquisador, envolvendo todos os sujeitos da pesquisa. Por fim, os Grupos de Interlocução na Pesquisa em Educação ou mesmo a pesquisa no âmbito das Ciências Sociais ligadas ao Materialismo Histórico Dialético constitui-se como espaço de produção de conhecimento favorável a esta teoria. Mais que isso, proporciona aos sujeitos da pesquisa refletir coletivamente e, deste modo, agir sobre o espaço em que atuam, repensando os fenômenos que constituem o contexto em que estão inseridos e por sua vez, potencializando a crítica e a produção de conhecimento do grupo. 


\section{REFERÊNCIAS}

ARISTOTELES, A política. Tradução Roberto Leal Ferreira. São Paulo: Martins Fontes, 2006.

BENJAMIN, W. Magia e técnica, arte e política: ensaios sobre literatura e histórica da cultura. Tradução Sergio Paulo Rouanet. São Paulo: Brasiliense, 1994.

CEZAR, T. T. Um estudo sobre o trabalho das pedagogas no Instituto Federal Farroupilha: historicidades, institucionalidades e movimentos. 2014. 160 f. Dissertação (Mestrado em Educação)- Universidade Federal de Santa Maria, Santa Maria, RS, 2014.

FERREIRA, L. S. et al. Grupos de interlocução como técnica de produção e sistematização na pesquisa em educação. Revista Diálogo Educacional, Curitiba, v. 14, n. 41, p. 191-209, jan./abr. 2014.

FERREIRA, L. S. Trabalho, profissionalidade e escola no discurso das professoras dos anos iniciais do Ensino Fundamental. 2006. 293 f. Tese (Doutorado em Educação) - Universidade Federal do Rio Grande do Sul, Porto Alegre, 2006.

FIORIN, B. P. A. Trabalho e Pedagogia: considerações a partir dos discursos de pedagogas na escola. 2012. 100 f. Dissertação (Mestrado em Educação)- Universidade Federal de Santa Maria, Santa Maria, RS, 2012.

FRIGOTTO, G. A produtividade da escola improdutiva. 9. ed. São Paulo: Cortez, 2010.

KOSIK, K. Dialética do concreto. Tradução Célia Neves e Alderico Toríbio. 2. ed. Rio de Janeiro: Paz e Terra, 1976.

KUHN, T. S. A estrutura das revoluções cientificas. Tradução Beatriz Vianna Boeira e Nelson Boeira. São Paulo: Perspectiva, 1978.
LUKÁCS, G. Prolegômenos para uma ontologia do ser social: questões de princípios para uma ontologia hoje tornada possível. Tradução Lya Luft e Rodinei Nascimento. São Paulo: Boitempo, 2010.

MARASCHIN, M. S. Dialética das Disputas: trabalho pedagógico a serviço da classe trabalhadora? 2015. Tese (Doutorado em Educação) - Universidade Federal de Santa Maria, Santa Maria, RS, 2015.

MARQUES, M. O. Educação/interlocução, aprendizagem/reconstrução de saberes. Ijuí: Editora UNIJUÍ, 1996.

MARTINEZ, F. J. "A Filosofia da Práxis de Adolfo Sánchez Vázquez". In: VÁZQUEZ, A. S. Filosofia da práxis. Buenos Aires: Consejo Latinoameriano de Ciências Sociales (CLACSO); São Paulo: Expressão Popular, 2007. p. 11-18.

MARX, K. Contribuição à crítica da economia política. Tradução Florestan Fernandes. 2. ed. São Paulo: Expressão Popular, 2008.

RODRIGUES, I. D. W. M. O trabalho dos professores na escola e a busca por excelência: um estudo sobre mecanismos de avaliação. 2013. 103 f. Dissertação (Mestrado em Educação) - Universidade Federal de Santa Maria, Santa Maria, RS, 2013.

TRIVIÑOS, A. N. S. Introdução à pesquisa em ciência sociais: a pesquisa qualitativa em educação. São Paulo: Atlas, 2008.

VIEIRA PINTO, Á. Ciência e existência: problemas filosóficos da pesquisa científica. Rio de Janeiro: Paz e Terra, 1969. 